\title{
Cancer Caregiving and Health Information Technology: An Analysis of the Health Information National Trends (HINTS) Survey
}

\section{Victoria R. Nelson}

MSU ComArtSci: Michigan State University College of Communication Arts and Sciences

Katharine M. Mitchell

MSU ComArtSci: Michigan State University College of Communication Arts and Sciences

Bree E Holtz ( $\square$ bholtz@msu.edu )

Michigan State University https://orcid.org/0000-0001-8832-0049

\section{Research Article}

Keywords: caregiving, cancer, health technology, HINTS

Posted Date: November 10th, 2021

DOI: https://doi.org/10.21203/rs.3.rs-957874/v1

License: (c) (i) This work is licensed under a Creative Commons Attribution 4.0 International License.

Read Full License 


\section{Abstract}

Purpose: In this paper, we explore how health technology use impacts informal caregivers' health and how sociodemographic factors are related, using the Health Information National Trends Survey (HINTS).

Methods: Data for this study were obtained from the National Cancer Institutes' Health Information and National Trends Survey (HINTS 5, Cycle 2, 2018). Participants for the current study were chosen based on their response to one question related to their caregiving status. The sample size was 483 respondents. Variables of interest included caregiver relationship type, general technology use, portal use, and overall health status.

Results: The results indicate that there was not a significant difference of caregiving role on portal usage, $\left[F(5,99)=.975, p=.44, \eta^{2}=.049\right]$, and technology use $[F(7,462)=2.625, p=.01]$. This demonstrates that those caregiving for a child are more likely to use technology for health related issues. There was not a significant effect of portal use on caregiver health. However, there was a significant effect of technology use on overall health $(\mathrm{t}=2.074, p=.04)$. There was also a significant effect of demographics on general technology use $[F(7,434)=14.858, p<.001]$. Demonstrating as education and income increases, technology use also increases, and as age increases technology use decreases.

Conclusion: This study affirmed that demographic inequalities can negatively impact technology and portal use, which could reduce the burden on caregivers. Therefore, it is important to work to engage cancer patients and their caregivers with technological support and resources.

\section{Introduction}

Approximately 25 percent of US adults, 18 and older, participate in some type of informal caregiving, and this percentage is likely to increase as the population continues to age and need greater assistance [1]. It is expected there will be 71 million people over the age of 65 by 2030, meaning the number of people over the age of 65 will double from the year 2000 to 2030 [1]. However, caregiving is not only needed for aging adults, but also for young adults and children with chronic illness [2, 3] and disabilities [4]. Caregiving requires a great deal of responsibility and can have negative impacts on the caregiver such as depression and anxiety $[7,8,9,10,11]$. This has been found to be especially true for those who take care of loved ones with cancer in comparison to other health conditions like diabetes [5]. Cancer caregivers have reported feeling economical, physical, emotional, and psychosocial burdens [7]. Finding ways to support caregivers is critical to improving their overall wellbeing. Health technologies have been shown to be one effective way of improving caregivers' perceptions of the burden of caregiving [12]. This paper examines technology use among cancer and other caregivers using data from the Health Information National Trends Survey (HINTS).

\section{Caregiving}


Informal or family caregivers are defined as family members, friends or other individuals who assist in the needs of a patient's healthcare needs without financial compensation [13]. Providing this type of care is a demanding job, that often includes cleaning, making meals, transit to medical appointments, medication dispensing, and a wide range of other necessary tasks [14]. Furthermore, some caregivers sometimes called the "Sandwich Generation" - are caring for both older parents and their children at the same time, increasing the strain on caregivers [15].

These tasks have been found to have an impact on the caregiver's mental and physical wellbeing. Caregiving can cause negative emotional and physical effects $[16,17,18]$. Studies have found that these negative effects can include higher prescription drug use, smoking, poor food choices, and an overall lower self-perceived health $[19,20]$. Exploring ways to alleviate the negative impacts on caregivers is critical to their health outcomes and overall well-being. Health information technology has the potential to alleviate some of the negative impacts on caregivers to improve overall health outcomes and well-being.

\section{Health technology and caregiving}

Technology has been shown to be one potential method for easing the burden on caregivers [10]. The use of technology by long-distance family caregivers of elderly loved ones can improve social and emotional cognition, allowing for more frequent wellness check-ins and increased communication [21, 22]. Health information communication technologies have been shown to improve decision confidence, reduce emotional strain and caregiver burden [23]. A review of studies focusing on cancer caregiving have shown that health information technology can help reduce caregiver burden and increase feelings of empowerment [24]. Research has demonstrated that health quality and social connectedness can be improved through the use of health technology $[22,25]$. Several studies have found that technology use can improve several facets of social support, knowledge, and quality of life, while also decreasing instances of depression and anxiety $[3,18,26,27]$.

Another area of technology is the use of health portals by caregivers to help support their navigation of the healthcare system for the patient. Health portals are online tools where patients can access information about their medical care such as appointments, medical notes, and medication lists. Many older patients do not use health portals [28], sometimes due to access or literacy issues. However, this is also in part because they are frequently being actively excluded by health care providers who assume they are incapable or unwilling to engage with the technology [29]. This exclusion trickles down to those elderly patients' family caregivers, barring them from benefiting from the usage of these technologies [30]. The use of health portals by caregivers has been shown to be beneficial especially to those individuals who are unable to coordinate their own care; however, their use by informal caregivers is limited by HIPAA regulations [31]. This can mean that caregivers have a difficult time accessing technology that can reduce their caregiving burden.

\section{Influence of demographics}


Due to this caregiving burden, caregivers are relying more and more on technology for assistance in caring for their loved ones [21]. Yet there remain limitations on the use of these technologies. There is also evidence that the demographic characteristics of caregiving individuals affect how often they are able and willing to use technology for health-related purposes. Characteristics such as race, ethnicity, English language proficiency, and socio-economic status have all been implicated as possible barriers to technology adoption $[32,33,34,35,21]$. This study attempts to investigate an adjacent set of questions.

What remains unknown is if there a difference in overall technology use depending on caregiver role (i.e. caregiving for a child/parent/spouse). Therefore, the objective of this paper is to explore the relationship of caregiving, demographics of caregivers and impacts of technology. Our research questions include, does overall technology use a) predict and $b$ ) moderate the overall health status of caregivers? And does (a) age, (b) marital status, (c) race/ethnicity, (d) income, or (e) gender predict the use of health technologies of caregivers?

\section{Method}

\section{Study design and sample}

Data for this study were obtained from the Health Information National Trends Survey 5 (HINTS 5 Cycle 2), which was collected in 2018. The survey was created by the National Cancer Institute to gather information on health-related trends and patterns for US citizens. The HINTS survey was completed through a mailed questionnaire to a nationally representative US sample through a random selection of respondents. The HINTS survey was completed by 3,504 respondents [36].

Participants for the current study were chosen based on their response to one question related to their caregiving status. Those who indicated they were not caregivers or failed to answer the question (i.e., missing data) were removed from the sample. A respondent was characterized as a caregiver if they indicated they cared for either a Child, Parent, Spouse, Another Family Member, Friend, or some combination of these roles. Most respondents were caring for either a Child (23.2\%), Parent (25.9\%), Spouse (17.2\%), or Another Family Member (10.6\%). The sample consisted of 483 respondents. The majority of those were White $(66 \%)$, females $(65.6 \%)$, who had at least some college education or more (71.8\%), and were between the ages of 40 and 70 years old (66.9\%).

\section{Outcome variable}

The technology use variable was created using questions B5a-g, see Figure 1. Example items include, "In the past 12 months have you used a computer, smartphone, or other electronic means to look for health or medical information?" and "In the past 12 months have you used a computer, smartphone, or other electronic means to track health care charges?" Response options included $1=$ Yes, $2=$ No. These items were selected as indicators of the respondents owning and using a type of personal technology device for health-related purposes. 
The portal use variable was created using questions D8a-g and D9a-e, see Figure 2. Example items include, "In the past 12 months have you used your online medical record to request a refill of medications?" and "Do any of your online medical records include a list of health/medical problems?" Response options included $1=$ Yes, $2=$ No. These items were selected as they were indicators of respondents using a health portal for various health activities.

Overall health status was measured using question G1: "In general, would you say your health is..." Response options included $1=$ Excellent, $2=$ Very good, $3=$ Good, $4=$ Fair, and $5=$ Poor.

\section{Sample characteristics}

Demographic variables included age, sex, occupational status, marital status, education level, race/ethnicity, and income.

\section{Statistical methods}

Statistical analyses were conducted using SPSS (v.26). Descriptive statistics were conducted to summarize the sample characteristics and study variables. Between-group differences based on caregiving status were explored for research question one using an analysis of variance (ANOVA) test. To compare each of the caregiving conditions to every other condition, Tukey HSD tests were run. In order to perform the post-hoc tests, the caregiving status variable was re-coded to indicate single caregiving relationships, two relationships into a combined variable, and three or more types of relationships in a separate variable. Linear regression was used to test the relationships in research questions two and three. In addition, moderation analysis was conducted using PROCESS v3.3 [37] to test the moderation of a) portal use and b) technology use on the relationship between caregiver role and overall health. For the technology use variable created using questions B5a-g, we created one variable by adding all of the items together recoded the items and the HINTS data set coded each item 1= yes they used a technology and $2=$ no they did not use the technology (i.e. for the average variable we created, a higher number means lower technology usage).For the portal use variable created using questions D8a-g and D9a-e, we created one variable by adding all of the items together, a higher number indicating lower usage.

\section{Results}

\section{Sample characteristics}

This analysis included individuals who completed the portion of the HINTS survey for caregivers ( $\mathrm{n}=$ 483). The caregivers were most often caring for either their parents $(25.9 \%)$ or their children $(23.2 \%)$, see Table 1 for all participant demographics and for caregiving role frequency. 
Table 1

Participant Demographics

\begin{tabular}{|c|c|}
\hline Variable & Frequency (\%) \\
\hline $\mathbf{N}$ & 483 \\
\hline \multicolumn{2}{|l|}{ Age (years) } \\
\hline Under 20 & $3(.6)$ \\
\hline $20-29$ & $21(4.2)$ \\
\hline $30-39$ & $47(9.5)$ \\
\hline $40-49$ & $86(17.7)$ \\
\hline $50-59$ & $125(25.9)$ \\
\hline $60-69$ & $112(23.3)$ \\
\hline $70-79$ & $62(12.7)$ \\
\hline $80-89$ & $17(3.4)$ \\
\hline 90 and above & $4(.8)$ \\
\hline \multicolumn{2}{|l|}{ General Health } \\
\hline Excellent & $59(12.4)$ \\
\hline Very Good & $178(37.5)$ \\
\hline Good & $154(32.4)$ \\
\hline Fair & $73(15.4)$ \\
\hline Poor & $11(2.3)$ \\
\hline \multicolumn{2}{|l|}{ Gender } \\
\hline Male & $139(28.8)$ \\
\hline Female & $317(65.6)$ \\
\hline \multicolumn{2}{|l|}{ Education Level } \\
\hline Less than 8 years & $4(.8)$ \\
\hline 8 through 11 years & $27(5.6)$ \\
\hline 12 years or completed high school & $69(14.3)$ \\
\hline Post high school training other than college & $31(6.4)$ \\
\hline Some college & $120(24.8)$ \\
\hline College graduate & $137(28.4)$ \\
\hline
\end{tabular}




\begin{tabular}{|c|c|}
\hline Variable & Frequency (\%) \\
\hline Postgraduate & $90(18.6)$ \\
\hline \multicolumn{2}{|l|}{ Marital Status } \\
\hline Single, never married & $78(16.1)$ \\
\hline Married & $275(56.9)$ \\
\hline Widowed & $24(5)$ \\
\hline Divorced & $69(14.3)$ \\
\hline Separated & $13(2.7)$ \\
\hline Living as Married & $18(3.7)$ \\
\hline \multicolumn{2}{|l|}{ Occupational Status } \\
\hline Employed & $247(51.1)$ \\
\hline Other - Specify & $5(1)$ \\
\hline Unemployed & $22(4.6)$ \\
\hline Homemaker & $37(7.7)$ \\
\hline Student & $6(1.2)$ \\
\hline Retired & $117(24.2)$ \\
\hline Disabled & $34(7)$ \\
\hline \multicolumn{2}{|l|}{ Annual Income } \\
\hline$\$ 0-9,999$ & $32(6.6)$ \\
\hline$\$ 10,000-14,999$ & $20(4.1)$ \\
\hline$\$ 15,000-19,999$ & $16(3.3)$ \\
\hline$\$ 20,000-34,999$ & $65(13.5)$ \\
\hline$\$ 35,000-49,999$ & $80(16.6)$ \\
\hline$\$ 50,000-74,999$ & $61(12.6)$ \\
\hline$\$ 75,000-99,999$ & $47(9.7)$ \\
\hline$\$ 100,000-199,999$ & $86(17.8)$ \\
\hline$\$ 200,000$ or more & $37(7.7)$ \\
\hline \multicolumn{2}{|l|}{ Race } \\
\hline White & 319 (66) \\
\hline
\end{tabular}




\begin{tabular}{|ll|}
\hline Variable & Frequency (\%) \\
\hline Black & $85(17.6)$ \\
\hline American Indian or Alaska Native & $3(.6)$ \\
\hline Multiple races selected & $19(3.9)$ \\
\hline Asian Indian & $7(1.4)$ \\
\hline Chinese & $5(1)$ \\
\hline Vietnamese & $2(.4)$ \\
\hline Other Asian & $6(1.2)$ \\
\hline Other Pacific Islander & $1(.2)$ \\
\hline Caregiving Status & \\
\hline Child & $112(23.2)$ \\
\hline Spouse & $83(17.2)$ \\
\hline Parent & $125(25.9)$ \\
\hline Another Family Member & $51(10.6)$ \\
\hline Friend & $16(3.3)$ \\
\hline Professional & $4(.8)$ \\
\hline Two Caregiving Relationships & $81(16.7)$ \\
\hline Three or More Caregiving Relationships & $11(2.28)$ \\
\hline
\end{tabular}

For the first study question, a one-way between subjects ANOVA was conducted to compare the difference between caregiver roles on portal use. Results suggest that there was not a significant difference of caregiving role on portal usage, $\left[F(5,99)=.975, p=.44, \eta^{2}=.049\right]$. We also compared the difference between caregiver role on general technology use. ANOVA results suggest a significant effect of caregiving role on general technology usage $\left[F(7,462)=2.625, p=.01, \eta^{2}=.039\right]$. Post hoc comparisons using the Tukey HSD test indicated that the mean score for caregiving for a child $(M=1.45$, $S D=.31)$ was significantly different than the caregiving for another family member condition $(M=1.61$, $\mathrm{SD}=.31$ ) indicating that those caregiving for a child are more likely to use technology for health-related issues.

The second question asks if health portals and technology use predicts the caregivers' reported overall health status. Results from linear regression indicate there was no significant effect of health portal use on overall caregiver health $(t=.946, p=.35)$. There was, however, a significant effect of technology use on the overall health of caregivers $(t=2.074, p=.04)$ demonstrating that using technology improves the 
health of caregivers, see Table 2. We also explored if health portal use and technology use moderate the relationship between caregiving status and overall health. Results suggest that health portal use nor general technology use were not significant moderators of the caregivers' health.

Table 2

Linear Regression Results of Portal Use and Technology Use Predicting Overall Health

\begin{tabular}{|c|c|c|c|c|c|}
\hline & B & SE B & b & $t$ & $p$ \\
\hline Portal Use & 0.426 & 0.450 & 0.096 & 0.946 & 0.35 \\
\hline Tech Use & 0.302 & 0.146 & 0.097 & 2.074 & 0.04 \\
\hline
\end{tabular}

The final research question asks if there were differences in the relationship between demographic variables and health portals and technology use. Results from linear regression suggest that there was not a significant effect of demographics on health portals use $[F(7,96)=1.5338, p=.17]$. However, there was a significant effect of demographic characteristics on general technology use $[F(7,434)=14.858, p<$ .001], see Table 3. Results suggest a negative, significant relationship between education and technology use $(\beta=-.034, t=-4.627, p<.001)$, and income and technology use $(\beta=-.017, t=-4.973, p<.001)$, which indicated that as education and income increases, technology use also increases. Results also suggest a positive, significant relationship between age and technology use $(\beta=.005, t=5.631, p<.001)$, and gender and technology use $(\beta=.018, t=2.508, p=.01$. These results indicate that as age increases, technology use decreases; single individuals have increased technology use; and females have increased technology use. See Table 4 for the means and standard deviations for demographics on health portal and technology use. 
Table 3

Linear Regression Results for Demographics Predicting Portal Use and Tech Use

\begin{tabular}{|c|c|c|c|c|c|}
\hline \multicolumn{6}{|l|}{ Portal Use } \\
\hline & B & SE B & b & $t$ & $p$ \\
\hline Age & 0.003 & 0.002 & 0.161 & 1.409 & .16 \\
\hline Occupation & -0.006 & 0.013 & -0.054 & -0.493 & .62 \\
\hline Marital Status & 0.013 & 0.012 & 0.129 & 1.092 & .28 \\
\hline Education Level & -0.002 & 0.010 & -0.027 & -0.248 & .81 \\
\hline Race & -0.004 & 0.018 & -0.024 & -.237 & .81 \\
\hline Income & 0.013 & 0.008 & 0.188 & 1.751 & .08 \\
\hline Gender & -0.021 & 0.011 & -0.192 & -1.888 & .06 \\
\hline \multicolumn{6}{|c|}{ Note: adj. $R^{2}=.037$} \\
\hline \multicolumn{6}{|l|}{ Tech Use } \\
\hline & UB & SE B & $\mathrm{b}$ & $t$ & $p$ \\
\hline Age & 0.005 & 0.001 & 0.255 & 5.631 & .000 \\
\hline Occupation & -0.002 & 0.002 & -0.062 & -1.397 & .16 \\
\hline Marital Status & 0.020 & 0.007 & 0.142 & 3.101 & .002 \\
\hline Education Level & -0.034 & 0.007 & -0.220 & -4.627 & .000 \\
\hline Race & -0.007 & 0.012 & $-0 . .026$ & -0.589 & .56 \\
\hline Income & -0.017 & 0.004 & -0.241 & -4.973 & .000 \\
\hline Gender & 0.018 & 0.007 & 0.114 & 2.508 & .013 \\
\hline
\end{tabular}


Table 4

Means and Standard Deviations for the Demographic Information for Portal Use and Tech Use

\begin{tabular}{|c|c|c|}
\hline \multirow[t]{2}{*}{ Variable } & Portal Use & Tech Use \\
\hline & $M(S D)$ & $M(S D)$ \\
\hline Age & $53.01(11.91)$ & $54.61(15.61)$ \\
\hline Occupation & $2.24(1.85)$ & $3.19(8.78)$ \\
\hline Marital Status & $2.04(2.09)$ & $2.27(2.21)$ \\
\hline Education Level & $5.34(2.44)$ & $5.06(2.01)$ \\
\hline Race & $1.55(1.22)$ & $1.57(1.20)$ \\
\hline Income & $6.31(3.03)$ & $4.70(4.32)$ \\
\hline Gender & $1.42(1.92)$ & $1.36(1.94)$ \\
\hline \multicolumn{3}{|c|}{$\begin{array}{l}\text { Note: Occupation ( } 1 \text { = employed, } 2 \text { = unemployed, } 3 \text { = homemaker, } 4 \text { = student, } 5 \text { = retired, } 6 \text { = } \\
\text { disabled); }\end{array}$} \\
\hline \multicolumn{3}{|c|}{$\begin{array}{l}\text { Marital Status ( } 1 \text { = married, } 2 \text { = living as married, } 3=\text { divorced, } 4 \text { = widowed, } 5 \text { = separated, } 6=\text { single, } \\
\text { never married); }\end{array}$} \\
\hline \multicolumn{3}{|c|}{$\begin{array}{l}\text { Education Level }(1=\text { Less than } 8 \text { years, } 2=8 \text { through } 11 \text { years, } 3=12 \text { years or completed high school, } \\
4=\text { Post high school training other than college, } 5=\text { Some college, } 6=\text { College graduate, } 7= \\
\text { Postgraduate); }\end{array}$} \\
\hline \multicolumn{3}{|c|}{$\begin{array}{l}\text { Race }(1=\text { white, } 2=\text { black, } 3=\text { American Indian or Alaska Native, } 4=\text { Asian, } 5=\text { Native Hawaiian or } \\
\text { Pacific Islander, } 6=\text { multiple races selected }) \text {; }\end{array}$} \\
\hline \multicolumn{3}{|c|}{$\begin{array}{l}\text { Income }(1=\$ 0 \text { to } \$ 9,999,2=\$ 10,000 \text { to } \$ 14,999,3=\$ 15,000 \text { to } \$ 19,999,4=\$ 20,000 \text { to } \$ 34,999,5= \\
\$ 35,000 \text { to } \$ 49,999,6=\$ 50,000 \text { to } \$ 74,999,7=\$ 75,000 \text { to } \$ 99,999,8=\$ 100,000 \text { to } \$ 199,999,9= \\
\$ 200,000 \text { or more); }\end{array}$} \\
\hline \multicolumn{3}{|c|}{ Gender ( 1 = male, 2 = female $)$. } \\
\hline
\end{tabular}

\section{Discussion}

We used a nationally representative, population-based survey to explore health portals use and technology use among caregivers as well as other demographic considerations. These results show the type of caregiving role does not have an effect on health portal use. However, the type of caregiving role influences general technology use for health. Specifically, results show that those caregiving for a child compared to another family member are more likely to use technology for health purposes. It is possible that caregivers of children may be younger than those caring for another family member, and age has been found to be a significant driver of more technology use in general $[3,38]$. Future research should consider why this did not hold true for health portals usage.

Health portals use does not appear to predict a caregivers' overall health. Health portals use may not be as burden-reducing for caregivers due to the regulatory barriers that do not allow for easy access to the 
loved one's records making it harder to access the health portal initially [30]. Additionally, health portals can be difficult to navigate, and every hospital group requires the patient or caregiver to create a new account, which can be especially challenging for cancer caregivers as they already face a greater burden than other caregivers [5]. This lack of interoperability of health portal systems is a barrier to their widespread adoption by caregivers [39]. Additionally, there were no significant effects of demographic characteristics on health portals use. Although health portals use for in-home caregivers has increased [40], it remains a barrier as use requires knowledge and English language proficiency. These barriers may be even more deleterious for already overwhelmed cancer caregivers $[5,34,41]$.

General technology usage, like the use of a smartphone or computer, does not require such specific knowhow and may reduce caregiver burden due to stress reducing information seeking attributes [3]. This supports other findings in that the use of smart phones and mobile devices are very popular among all caregivers, but especially those over the age of 65 who are less likely to feel comfortable using technology [30]. For technology use, age, education, income, and gender had a significant effect. A major barrier to all technology use, including general technology use and health portals, is income and income has shown to impact technology adoption [2]. Level of education appears to also be influential akin to income. Furthermore, caregivers in this study used general technology for health at a greater frequency than health portals, which could explain why health portal use was not a significant predictor. Caregiving technologies may reduce burden, which may allow caregivers the ability to focus on their own health and well-being [3]. This can be especially true for cancer caregivers where studies have shown that health information technology can help reduce caregiver burden and increase feelings of empowerment [24]. Although health portal use and technology use are different and are used with different frequency, it is likely that both general technology and health portals are critical to aid caregivers [42].

\section{Limitations And Strengths}

As with any study, there are limitations that need to be acknowledged. First, the data relies on self-report and are cross-sectional so we cannot make any causal inferences. However, a major strength of this study is the use of a nationally representative dataset to begin exploring the impacts of health portal use and technology use among the various types of caregivers, which has been relatively understudied. Additionally, the vast differences in the use of health portals by health systems and physician offices were not measured through this survey. However, this does not mean that the results are inaccurate, rather the expense of using a secondary source of data of a nationally representative sample. Furthermore, many of the questions had yes/no responses, which does not provide a level of detail nor understanding that might help further understand the relationships between caregiving, technology use and overall health status.

This study provides an initial understanding of how health technology might be able to improve the caregiving experience for individuals. Future work can provide a further elucidation of the types of technology used and their impact on the perceptions of caregivers. Additionally, this work was unable to shed light on the social aspects of technology - the opportunity of giving and receiving social support - 
and that impact the overall health of the caregivers, which is also hypothesized to be critical. For instance, there have been past studies that have provided evidence that caregivers are very active on social media platforms [24].

\section{Conclusions}

This study examined the potential impact of health technology use and caregiver's health using a secondary source of a nationally representative sample. The data demonstrated that some health technologies do improve the overall health of caregivers. However, legal and technical barriers remain, which makes the use of health portals burdensome. This study also affirmed that inequalities related to race, gender, education, and income level all negatively influence the amount that technology and health portals could reduce the burden on caregivers allowing them to lead a fulfilling and healthy life. By understanding the needs of caregivers and how those needs differ depending on who they are providing care for, technologies can be tailored to better meet those needs.

\section{Declarations}

Funding: This research was not funded

Conflicts of interest/Competing interests: The authors report no conflicts of interest

Availability of data and material: The data is publicly available

Code availability: Not applicable

Authors' contributions: B.H. and K.M. conceived of the presented idea.

V.N. and K.M. wrote the manuscript with support from B.H. V.N. and K.M. performed the computations. B.H. supervised this work. All authors provided critical feedback and helped share the research, analysis and manuscript.

Ethics approval: Not applicable

Consent to participate: Not applicable

Consent for publication: Not applicable

\section{References}

1. Center for Disease Control and Prevention. Caregiving. (2019, November 25).https://www.cdc.gov/aging/caregiving/index.htm

2. Zulman DM, Piette JD, Jenchura EC, Asch SM, Rosland A-M. Facilitating Out-of-Home Caregiving Through Health Information Technology: Survey of Informal Caregivers' Current Practices, Interests, 
and Perceived Barriers. J Med Internet Res. 2013 Jul 10;15(7):123.

3. Lapid MI, Atherton PJ, Clark MM, Kung S, Sloan JA, Rummans TA. Cancer Caregiver: Perceived Benefits of Technology. Telemedicine and e-Health. 2015 Nov;21(11):893-902.

4. Kling A, Campbell PH, Wilcox J. Young Children With Physical Disabilities: Caregiver Perspectives About Assistive Technology. Infants \& Young Children. 2010 Sep;23(3):169-83.

5. Kim Y, Schulz R. Family Caregivers' Strains: Comparative Analysis of Cancer Caregiving With Dementia, Diabetes, and Frail Elderly Caregiving. J Aging Health. 2008 Aug 1;20(5):483-503.

6. Sun V, Raz DJ, Kim JY. Caring for the Informal Cancer Caregiver. Curr Opin Support Palliat Care. 2019 Sep;13(3):238-42.

7. Girgis A, Lambert S, Johnson C, Waller A, Currow D. Physical, Psychosocial, Relationship, and Economic Burden of Caring for People With Cancer: A Review. J Oncol Pract. 2013 Jul;9(4):197-202.

8. HINTS5_Cycle1_Annotated_Instrument_English.pdf [Internet]. [cited 2021 Mar 12]. Available from: https://hints.cancer.gov/docs/Instruments/HINTS5_Cycle1_Annotated_Instrument_English.pdf

9. Schulz R, Visintainer P, Williamson GM. Psychiatric and Physical Morbidity Effects of Caregiving. Journal of Gerontology. 1990 Sep 1;45(5):P181-91.

10. Schulz R, O’Brien AT, Bookwala J, Fleissner K. Psychiatric and physical morbidity effects of dementia caregiving: prevalence, correlates, and causes. Gerontologist. 1995 Dec;35(6):771-91.

11. Schulz R, Sherwood PR. Physical And Mental Health Effects Of Family Caregiving. Journal of Social Work Education. 2008 Sep;44(sup3):105-13.

12. Nicolson A, Moir L, Millsteed J. Impact of assistive technology on family caregivers of children with physical disabilities: a systematic review. Disability and Rehabilitation: Assistive Technology. 2012 Sep;7(5):345-9.

13. Cameron JI, Franche R-L, Cheung AM, Stewart DE. Lifestyle interference and emotional distress in family caregivers of advanced cancer patients. Cancer. 2002 Jan 15;94(2):521-7.

14. Schumacher KL, Stewart BJ, Archbold PG, Dodd MJ, Dibble SL. Family caregiving skill: development of the concept. Research in Nursing \& Health. 2000;23(3):191-203.

15. DePasquale N, Davis KD, Zarit SH, Moen P, Hammer LB, Almeida DM. Combining Formal and Informal Caregiving Roles: The Psychosocial Implications of Double- and Triple-Duty Care. J Gerontol B Psychol Sci Soc Sci. 2016 Mar 1;71(2):201-11.

16. Bom J, Bakx P, Schut F, van Doorslaer E. The Impact of Informal Caregiving for Older Adults on the Health of Various Types of Caregivers: A Systematic Review. The Gerontologist [Internet]. 2018 Nov 3 [cited 2020 Oct 23]; Available from: https://academic.oup.com/gerontologist/advancearticle/doi/10.1093/geront/gny137/5159652

17. Bauer J, Sousa-Poza A. Impacts of Informal Caregiving on Caregiver Employment, Health, and Family. Journal of Population Ageing. 2015;8(3):113-

145. doi:http://dx.doi.org.proxy1.cl.msu.edu/10.1007/s12062-015-9116-0 
18. Oberoi DV, White V, Jefford M, Giles GG, Bolton D, Davis I, et al. Caregivers' information needs and their "experiences of care" during treatment are associated with elevated anxiety and depression: a cross-sectional study of the caregivers of renal cancer survivors. Support Care Cancer. 2016;24(10):4177-86.

19. Zwart PL de, Bakx P, Doorslaer EKA van. Will you still need me, will you still feed me when I'm 64 ? The health impact of caregiving to one's spouse. Health Economics. 2017;26(S2):127-38.

20. Hoffman GJ, Lee J, Mendez-Luck CA. Health Behaviors Among Baby Boomer Informal Caregivers. Gerontologist. 2012 Apr 1;52(2):219-30.

21. Lindeman DA, Kim KK, Gladstone C, Apesoa-Varano EC. Technology and Caregiving: Emerging Interventions and Directions for Research. Gerontologist. 2020 Feb 14;60(Supplement_1):S41-9.

22. Benefield LE, Beck C. Reducing the distance in distance-caregiving by technology innovation. Clin Interv Aging. 2007 Jun;2(2):267-72.

23. Lucero RJ, Fehlberg EA, Patel AGM, Bjarnardottir RI, Williams R, Lee K, et al. The effects of information and communication technologies on informal caregivers of persons living with dementia: A systematic review. Alzheimers Dement (N Y). 2019;5:1-12.

24. Shin JY, Kang TI, Noll RB, Choi SW. Supporting Caregivers of Patients With Cancer: A Summary of Technology-Mediated Interventions and Future Directions. American Society of Clinical Oncology Educational Book. 2018 May 23;(38):838-49.

25. Sakaguchi-Tang DK, Bosold AL, Choi YK, Turner AM. Patient Portal Use and Experience Among Older Adults: Systematic Review. JMIR Med Inform [Internet]. 2017 Oct 16 [cited 2021 Mar 5];5(4). Available from: https://www.ncbi.nlm.nih.gov/pmc/articles/PMC5662789/

26. Whitten P, Holtz B. Provider Utilization of Telemedicine: The Elephant in the Room. Telemedicine and e-Health. 2008;14(9):995-997.

27. Ramirez-Zohfeld V, Seltzer A, Xiong L, Morse L, Lindquist LA. Use of Electronic Health Records by Older Adults, 85 Years and Older, and Their Caregivers. Journal of the American Geriatrics Society. 2020;68(5):1078-82.

28. Wolff JL, Darer JD, Larsen KL. Family Caregivers and Consumer Health Information Technology. J GEN INTERN MED. 2016 Jan 1;31(1):117-21.

29. Mynatt ED, Rowan J, Craighill S, Jacobs A. Digital family portraits: supporting peace of mind for extended family members. In: Proceedings of the SIGCHI Conference on Human Factors in Computing Systems [Internet]. New York, NY, USA: Association for Computing Machinery; 2001 [cited 2020 Sep 18]. p. 333-40. (CHI '01). Available from: https://doi.org/10.1145/365024.365126

30. Christie HL, Martin JL, Connor J, Tange HJ, Verhey FRJ, de Vugt ME, et al. eHealth interventions to support caregivers of people with dementia may be proven effective, but are they implementationready? Internet Interv [Internet]. 2019 Jul 24 [cited 2020 Sep 14];18. Available from: https://www.ncbi.nlm.nih.gov/pmc/articles/PMC6926245/

31. Shin JY, Kang TI, Noll RB, Choi SW. Supporting Caregivers of Patients With Cancer: A Summary of Technology-Mediated Interventions and Future Directions. Am Soc Clin Oncol Educ Book. 2018 May 
23;38:838-49.

32. Li L, Peng W. Does Health Information Technology Promote Healthy Behaviors? The Mediating Role of Self-Regulation. Health Commun. 2020 Dec;35(14):1772-81.

33. Kontos E, Blake KD, Chou W-YS, Prestin A. Predictors of eHealth Usage: Insights on The Digital Divide From the Health Information National Trends Survey 2012. Journal of Medical Internet Research. 2014;16(7):e172.

34. Goldzweig CL, Orshansky G, Paige NM, Towfigh AA, Haggstrom DA, Miake-Lye I, et al. Electronic Patient Portals: Evidence on Health Outcomes, Satisfaction, Efficiency, and Attitudes: A Systematic Review. Ann Intern Med. 2013 Nov 19;159(10):677.

35. Yoon H, Jang Y, Vaughan PW, Garcia M. Older Adults' Internet Use for Health Information: Digital Divide by Race/Ethnicity and Socioeconomic Status. J Appl Gerontol. 2020;39(1):105-10.

36. Blake, K. HINTS 5, Cycle 2 Dataset. NCIP Hub. 2019. doi:10.17917/JNFG-T497

37. Hayes, AF. Partial, conditional, and moderated moderated mediation: Quantification, inference, and interpretation. 2018. Communication Monographs, 85(1), 4-40.

38. Shaffer KM, Chow PI, Cohn WF, Ingersoll KS, Ritterband LM. Informal Caregivers' Use of InternetBased Health Resources: An Analysis of the Health Information National Trends Survey. JMIR Aging. 2018;1(2):e11051.

39. Otte-Trojel T, de Bont A, Rundall TG, van de Klundert J. What do we know about developing patient portals? a systematic literature review. J Am Med Inform Assoc. 2016 Apr;23(e1):e162-8.

40. Ochoa A, Kitayama K, Uijtdehaage S, Vermillion M, Eaton M, Carpio F, et al. Patient and provider perspectives on the potential value and use of a bilingual online patient portal in a Spanish-speaking safety-net population. J Am Med Inform Assoc. 2017 Nov 1;24(6):1160-4.

41. Woo K, Tark A, Baik D, Dowding D. Informal Caregiver Decision-Making Factors Associated With Technology Adoption and Use in Home Healthcare. Home Healthcare Now. 2019;37(6):328-336.

42. Resnick H, Alwan M. Use of health information technology in home health and hospice agencies: United States, 2007. Journal of the American Medical Informatics Association. 2010;17(4):389-395.

\section{Figures}




\section{B5. In the past 12 months, have you used a computer, smartphone, or other electronic means to do any of the following?}

Yes No

a. Looked for health or medical information for yourself.

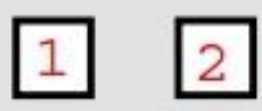
Electronic SelfHealthinfo

b. Looked for health or medical information for someone else Electronic HealthInfoSE

c. Bought medicine or vitamins online Electronic BuyMedicine

d. Looked for assistance for the care that you provide for someone else.......... 1

e. Used e-mail or the Internet to communicate with a doctor or a doctor's office.

\section{Electronic TalkDoctor}

f. Tracked health care charges and costs.....
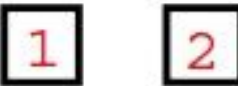

Electronic TrackedHealthCosts

g. Looked up medical test results Electronic_TestResults

Figure 1

HINTS Question B5. Available from:

https://hints.cancer.gov/docs/Instruments/HINTS5_Cycle2_Annotated_Instrument_English.pdf 
D8. In the past 12 months, have you used your online medical record to...

Yes No

a. Request refill of medications? .................... Recordsonline RefillMeds

b. Fill out forms or paperwork related to your health care?

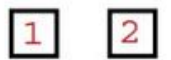
RecordsOnline Paperwork

c. Request correction of inaccurate information? Recordsonline_RequestCorrection

d. Securely message health care provider and staff (for example, e-mail)?

Recordsonline MessageHCP

e. Download your health information to your computer or mobile device, such as a cell phone or tablet? Recordsonline_DownloadHealth

f. Add health information to share with your health care provider, such as health concerns, symptoms, and side effects?....... 1 Recordsonline_AddHealthInfo

g. Help you make a decision about how to treat an illness or condition? Recordsonline_MakeDecision

D9. Do any of your online medical records include the following types of medical information?

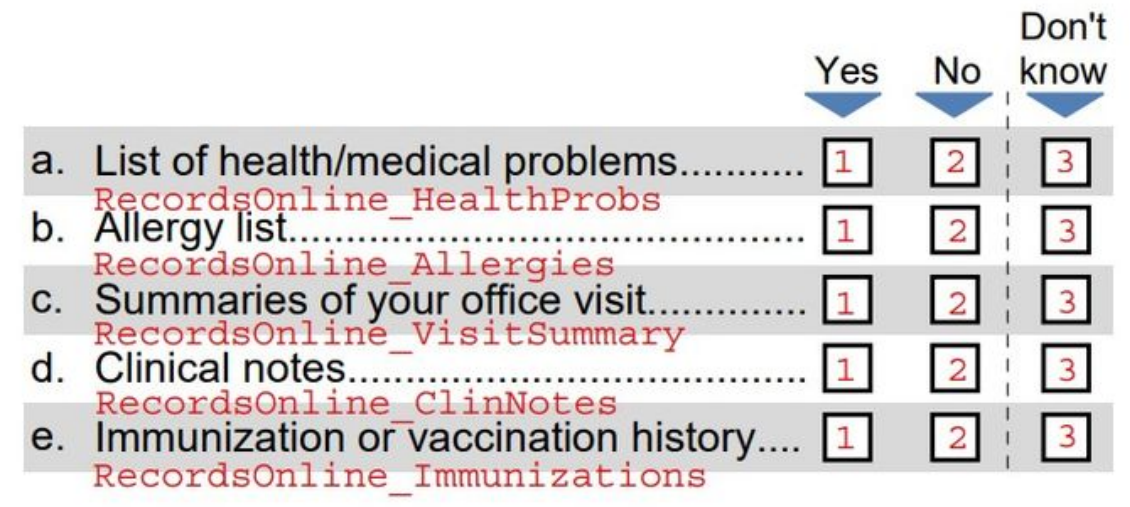

Figure 2

HINTS Questions D8 \& D9. Available from:

https://hints.cancer.gov/docs/Instruments/HINTS5_Cycle2_Annotated_Instrument_English.pdf 